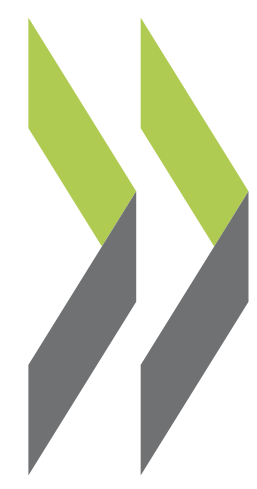

OECD Working Papers on Insurance and Private Pensions No. 16

\section{Evaluating the Impact of Risk Based Funding} Requirements on Pension Funds

\section{Jordy Peek,}

Andreas Reuss,

Gerhard Scheuenstuhl 


\section{\ęC}

\section{EVALUATING THE IMPACT OF RISK BASED FUNDING REQUIREMENTS ON PENSION FUNDS}

Jordy Peek, Andreas Reuss and Gerhard Scheuenstuhl

March 2008

OECD WORKING PAPER ON INSURANCE AND PRIVATE PENSIONS

No. 16

Financial Affairs Division, Directorate for Financial and Enterprise Affairs

Organisation for Economic Co-operation and Development

2 Rue André Pascal, Paris 75116, France

www.oecd.org/daf/fin/wp 


\begin{abstract}
RÉSUMÉ
Evaluating the Impact of Risk Based Funding Requirements on Pension Funds.

The objective of this study is to analyse what the quantitative funding requirements for pension funds with defined benefit plans would be, if Solvency II (based on the QIS 3 methodology) would be applied. Also possible extensions of the Solvency II methodology that seem necessary in order to reflect the specifics of pension funds will be discussed.
\end{abstract}

JEL codes: G18, G23, J32

Keywords: Pension funds, defined benefit, funding rules, investment, discount rates, accounting, valuation methods, actuarial methods, fair value.

$* * * * *$

Evaluating the Impact of Risk Based Funding Requirements on Pension Funds.

L'objectif de cette étude est d'analyser ce que seraient les besoins quantitatifs de financement pour des fonds de pension à prestations définies, si 'Solvabilité II' (basée sur la méthodologie de QIS 3) est appliquée. Les prolongements possibles de la méthodologie de 'Solvabilité II' qui semblent nécessaires afin de refléter les spécificités des fonds de pension seront également discutés.

Codes JEL: G18, G23, J32

Mots clés: organismes de retraite, prestation définie, règles de financement, investissement, taux d'actualisation, comptabilité, méthodes d'évaluation, méthodes actuarielles, juste valeur.

Copyright OECD, 2008

Applications for permission to reproduce or translate all, or part of, this material should be made to: Head of Publications Service, OECD, 2 rue André-Pascal, 75775 Paris Cédex 16, France. 


\title{
EVALUATING THE IMPACT OF RISK BASED FUNDING REQUIREMENTS ON PENSION FUNDS
}

\author{
by Jordy Peek, Andreas Reuss and Gerhard Scheuenstuhl ${ }^{1}$
}

\section{Introduction}

The target of this study is to evaluate the impact of risk based funding requirements on pension funds. This is achieved by performing quantitative analyses of risk based funding requirements based on an exemplary risk based valuation framework.

Within the European Union (EU), risk based funding requirements for insurance companies are currently being revised as part of the Solvency II project. Solvency II includes a fundamental and wideranging review of the current insurance directives with the target to ensure adequate policyholder protection in all EU member states. One of the main goals is that the quantitative funding requirements better reflect the true risk of an insurance undertaking.

In order to evaluate the impact of quantitative funding requirements under Solvency II, a number of Quantitative Impact Studies (QIS) have been performed. The most recent study is QIS 3, which summarizes the current status of the standard model for determining solvency requirements for insurance companies under Solvency II.

Although Institutions for Occupational Retirement Provision (IORPS) are not included in the scope of the Solvency II project, discussions are currently underway internationally as to whether the Solvency II requirements that will be introduced for insurance companies should be extended to pension funds as well. ${ }^{2}$ It is not intended to directly apply the Solvency II models developed for insurance companies to pension funds, but it does not seem unreasonable that the underlying principles will be similar. In particular, it seems possible that the QIS 3 model could be used as a starting point for such a modification.

The objective of this study is to analyse what the quantitative funding requirements for pension funds with defined benefit plans would be, if Solvency II (based on the QIS 3 methodology) would be applied.

\footnotetext{
${ }^{1}$ The authors are from the following institutions: Jordy Peek: Risklab Germany, Dr. Andreas Reuss: Institut für Finanz- und Aktuarwissenschaften and Dr. Gerhard Scheuenstuhl: Risklab Germany. The views expressed herein are those of the authors and do not necessarily reflect those of the OECD or the governments of its Member countries. The authors are solely responsible for any errors.

2 See McCreevy, C. "Closing address to the CEIOPS Conference 2007 - View from the Top", Proceedings of CEIOPS Conference 2007, Frankfurt (http://www.ceiops.eu/media/docman/public_files/Conference2006/CEIOPS\%20Conference-

McCREEVY-EC.pdf) and Terták, E. (2007), "The Supervisory Framework for Occupational Pensions Where Now and What Next?", Proceedings of CEIOPS Conference 2007, Frankfurt (http://www.ceiops.eu/media/docman/public_files/Conference2006/CEIOPSConference-ElemerTertakEC.pdf).
} 
We will also discuss possible extensions of the Solvency II methodology that seem necessary in order to reflect the specifics of pension funds.

It is beyond the scope of this study to discuss whether an introduction of Solvency II for pension funds is appropriate. This would require a much deeper analysis.

It is also important to understand that this study does not focus on pension funds in specific countries. Instead, a generic analysis is performed (based on certain assumptions regarding type of pension plan, mix of plan members, asset allocation and initial funding level). The various plan types represent a broad range of pension plan designs found throughout OECD countries.

The quantitative impact of Solvency II capital requirements will be shown for these generic pension plans and strategic asset allocations.

The study is organised as follows. In section 2, we describe the generic funds and the assumptions underlying the calculations. Section 3 summarizes the QIS 3 methodology and possible extensions to reflect the specifics of pension funds. The results of the calculations are presented in section 4.

\section{Scope and Assumptions}

In this section, we describe the characteristics of the generic pension funds analysed in this study and the major assumptions underlying the calculations.

\section{Pension Funds}

The quantitative analyses in this study are based on a limited number of generic pension funds, where a pension fund is defined as a combination of a pension plan and a plan member portfolio. The pension funds considered in this study are generic and do not intend to reflect pension funds in specific OECD countries.

Figure 1. Overview of generic pension funds

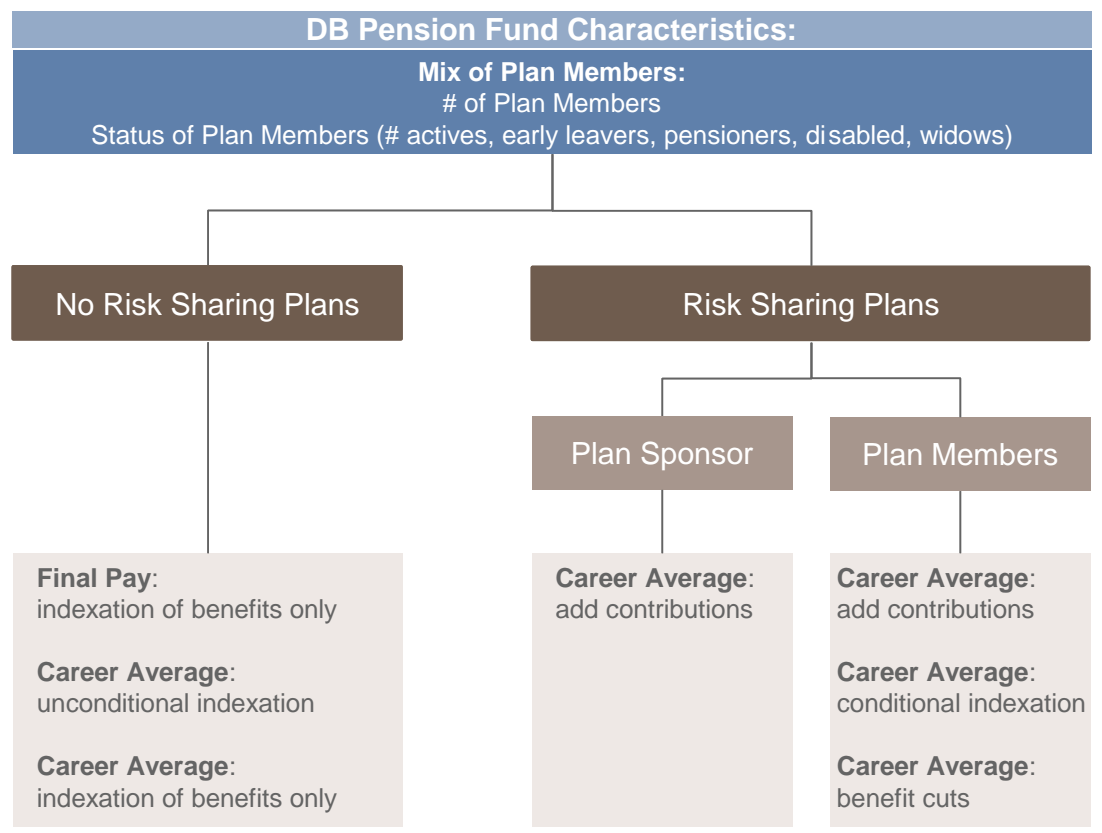


It is obviously not possible to analyse all types of pension plans. We therefore focus on characteristics of pension funds that are both relevant for risk based funding requirements and different from life insurance companies. Figure 1 gives an overview of the generic pension funds considered in this study.

\section{Mix of Plan Members}

The same synthetic mix of plan members is assumed for each of the pension plans described below. The number of plan members amounts to 10.000 and consists of $50 \%$ active members, $10 \%$ early leavers, $25 \%$ old-age pensioners, $5 \%$ disabled persons and $10 \%$ widows/widowers. Age, gender and salary distribution coincide with the assumptions made in a previous study. ${ }^{3}$ Assumptions about new members are not required as the valuation focuses on accrued benefits of existing members.

For sensitivity analyses, two alternative mixes have been assumed (see appendix):

- "Less Actives": 25\% active members, 5\% early leavers, $44 \%$ old-age pensioners, $9 \%$ disabled persons and $17 \%$ widows/widowers;

- "Retirees": $100 \%$ old-age pensioners.

\section{Pension Plans}

The focus of this study is on traditional Defined Benefit (DB) plans. Book value reserves, protected Defined Contribution (DC) and pure DC plans are outside the scope of the study.

Pension plans can be split into risk sharing plans and no risk sharing plans. Risk sharing plans contain features that allow the pension fund to mitigate the risk by sharing part of it with the sponsor and/or with the plan members. In pension plans without risk sharing, the risks stay within the pension fund. ${ }^{4}$

In a first step, generic pension plans that do not allow for risk sharing with the plan sponsor and/or the plan members are defined. These are the standard final pay and the standard career average plan. The main features of both plans are:

Final Pay (FP) Plan:

- The plan member receives $1 \%$ of the final salary for each year of service as pension benefit;

- Benefits are paid as life-long annuities and are indexed based on inflation (CPI);

- Accrued benefits for early leavers are indexed based on inflation (CPI).

(Indexed) Career Average Plan:

- For each year of service, the plan member earns a deferred benefit equal to $1 \%$ of the current salary;

\footnotetext{
${ }^{3}$ See Blome, S., Fachinger, K., Franzen, D., Scheuenstuhl, G., and Yermo, J. (2007), "Pension Fund Regulation and Risk Management: Results from an ALM Optimisation Exercise", in OECD Private Pension Series No. 8, Protecting Pensions: Policy Analysis and Examples from OECD Countries, Paris, OECD.

${ }^{4}$ In reality, almost all pension plans involve a plan sponsor. For presentational purposes, we first show results for plans without any risk sharing (i.e. with no plan sponsor involved).
} 
- Accrued benefits and pensions in payment are (unconditionally) indexed based on inflation (CPI).

In addition, another Career Average Plan with indexation only for pensions in payment has been considered.

The generic pension plans that do allow for risk sharing are career average (CA) plans with a risk sharing feature. The risk sharing features that we have considered are additional contributions, conditional indexation and benefit cuts.

An important risk sharing aspect of pension plans is the fact that the plan sponsor may be required to make additional contributions in case of underfunding. In a similar way, future contributions of plan members may be increased in an underfunding situation. These risk-sharing mechanisms do not occur in the life insurance sector and therefore deserve special attention.

Overall, there seems to be no general agreement on how to best reflect this type of risk sharing in a risk based funding framework such as Solvency II. Instead, discussions have shown that a contribution commitment by the sponsor could be reflected in the pension fund's solvency balance sheet in a number of different ways. For example, the sponsor's credit rating could be directly reflected in the calculation of the SCR (e.g. by taking into account future probabilistic solvency of the sponsoring company). Alternatively, the sponsor could be allowed to set up SCR in a separate fund (instead of increasing the funding of the pension fund itself). Both alternatives would reduce the pension fund's SCR (in some cases even to zero). Other protection mechanisms such as guaranteed protection funds (fire funds) as well as allowance for recovery periods might also be taken into account.

Another idea is to reduce the security level underlying the Solvency Capital Requirement (SCR) calculation. We will illustrate how the capital requirements change for the CA plan if the security level is reduced from $99.5 \%$ to $97.5 \% .^{5}$ We acknowledge that this is only illustrative and that further methodological work is necessary.

Another type of risk sharing between the pension fund and the plan members is conditional indexation of both accrued benefits and benefits in payment. ${ }^{6}$ The amount of indexation depends on the IAS 19 funding level of the pension fund.

A third type of risk sharing is where the pension fund is allowed to cut accrued benefits. We therefore consider a CA plan with the option to cut benefits in the case of underfunding.

\section{Assumptions}

Assumptions have been made regarding the valuation of liabilities, the asset portfolio and the initial funding level.

\section{Liabilities}

For valuation purposes, the demographic evolution of plan members is projected using mortality and morbidity assumptions normally used for occupational DB plans in Germany (so called Heubeck

\footnotetext{
${ }^{5}$ This could be refined by defining the security level depending on the credit rating of the sponsoring company.

${ }^{6}$ This could be considered as some type of hybrid DB plan.
} 
Richttafeln $2005 \mathrm{G}$ ). ${ }^{7}$ These reflect best estimate mortality and disability probabilities (no security margins) that include an allowance for future increase of life expectancy (trend function). Expected age at death for various ages and generations is shown in Figure 2.

Figure 2. Expected age at death for various ages and generations

\begin{tabular}{|c|c|c|c|c|c|c|}
\hline \multirow{2}{*}{ age } & \multicolumn{2}{|c|}{$\mathbf{4 5}$} & \multicolumn{2}{c|}{$\mathbf{6 5}$} & \multicolumn{2}{c|}{$\mathbf{8 5}$} \\
in year & male & female & male & female & male & female \\
\hline $\mathbf{2 0 0 7}$ & 82,5 & 87,7 & 82,9 & 87,0 & 90,2 & 91,2 \\
$\mathbf{2 0 1 7}$ & 84,0 & 89,1 & 84,3 & 88,3 & 90,7 & 91,9 \\
$\mathbf{2 0 2 7}$ & 85,5 & 90,4 & 85,6 & 89,6 & 91,2 & 92,6 \\
$\mathbf{2 0 3 7}$ & 86,8 & 91,6 & 86,9 & 90,8 & 91,7 & 93,2 \\
$\mathbf{2 0 4 7}$ & 88,1 & 92,8 & 88,2 & 92,0 & 92,3 & 93,9 \\
\hline
\end{tabular}

Similar to IAS 19, allowance for future salary increases is made in the valuation of liabilities. Salaries are assumed to increase annually by productivity growth (1.7\%), by advancement in one's job or position $(0.25 \%)$ and by last year's inflation (CPI, which has been modelled stochastically).

Allowance for administrative expenses has been made. Unit costs of 500 monetary units have been assumed, which increase annually by inflation. The administrative expenses are equal to the square root of the number of plan members (actives and retirees) multiplied with the unit costs.

\section{Assets}

The strategic asset allocation (SAA) has an important impact on the risk based funding requirements of the pension fund under Solvency II.

The asset allocation of pension funds differs within countries but also between countries. Pension funds in Anglo-Saxon countries generally invest a larger share of their assets in equity and alternative investments than pension funds in continental Europe, which tend to have a greater focus on fixed income investments ${ }^{8}$.

We have assumed three (from an asset only perspective) mean-variance efficient asset allocations in accordance with typical asset allocations of pension funds we observed in OECD countries. These asset allocations are shown in Figure 3

For each SAA, the fixed income portfolio is split into $60 \%$ government bonds and $40 \%$ corporate bonds (where latter entail credit spread risk) and has a duration of 10 years. The corporate bonds are primarily invested in investment grade bonds. In addition, we assumed that 5\% of the total asset portfolio would be invested in foreign currency (leading to currency risk). Furthermore, no concentration of more than $3 \%$ of the total asset portfolio invested in one counterparty was supposed (no concentration risk).

\footnotetext{
${ }^{7}$ See Heubeck, K., Herrmann, R. and D'Souza, G. (2006), ”Die Richttafeln 2005 G - Modell, Herleitung, Formeln“, in Blätter der DGVFM, p. 473-517.

${ }^{8}$ See Mercer Investment Consulting (2007), "Asset allocation survey: European institutional market place overview“, p. 2.
} 
Figure 3. Specification of different Asset Allocations
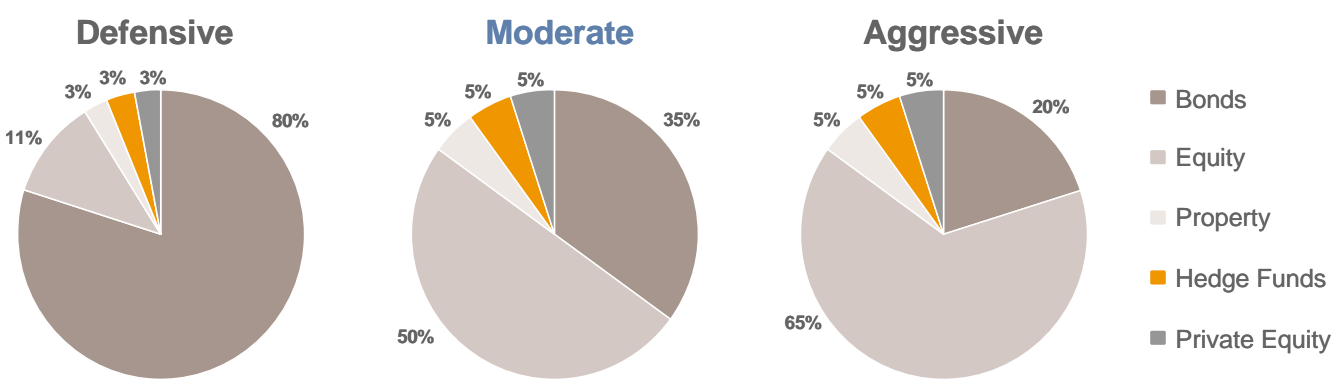

The moderate asset portfolio will be used in the main part of this study. We refer to the appendix for the results of the other two SAA.

\section{Funding Level}

In order to have a well-understood starting point for the quantitative analyses, we assume an initial funding level of $100 \%$ based on an IAS 19 valuation of liabilities (and assets shown at market value). This means that the amount of assets is equal to the IAS 19 DBO (calculated using the Projected Unit Credit method).

We understand that funding levels of pension funds vary significantly between countries and between different types of pension funds. In addition, funding levels are often measured on specific local accounting rules and when measured on IAS 19 basis differ significantly between countries. In subsequent sections, we will show the minimum required funding level under IAS 19 that is needed to be in compliance with the Solvency II funding requirements.

\section{Solvency II Methodology}

This section summarizes the main features of the Solvency II methodology for determining quantitative funding requirements. First, we describe the QIS 3 framework, which summarizes the current status of the standard model for insurance companies. Then, we discuss possible extensions of this model in order to better reflect the specifics of pension funds. This discussion focuses on specific characteristics of pension funds and therefore does not cover the basic principles underlying the methodology (such as choice of time horizon and risk measure).

\section{QIS 3 Framework}

The QIS 3 model consists of two building blocks:

1. Market consistent valuation of pension liabilities ("Technical Provisions");

2. Calculation of the Solvency Capital Requirement (“SCR").

These will be discussed in turn. The QIS 3 model is summarized in Figure 4. 
Figure 4. Overview of QIS 3 model

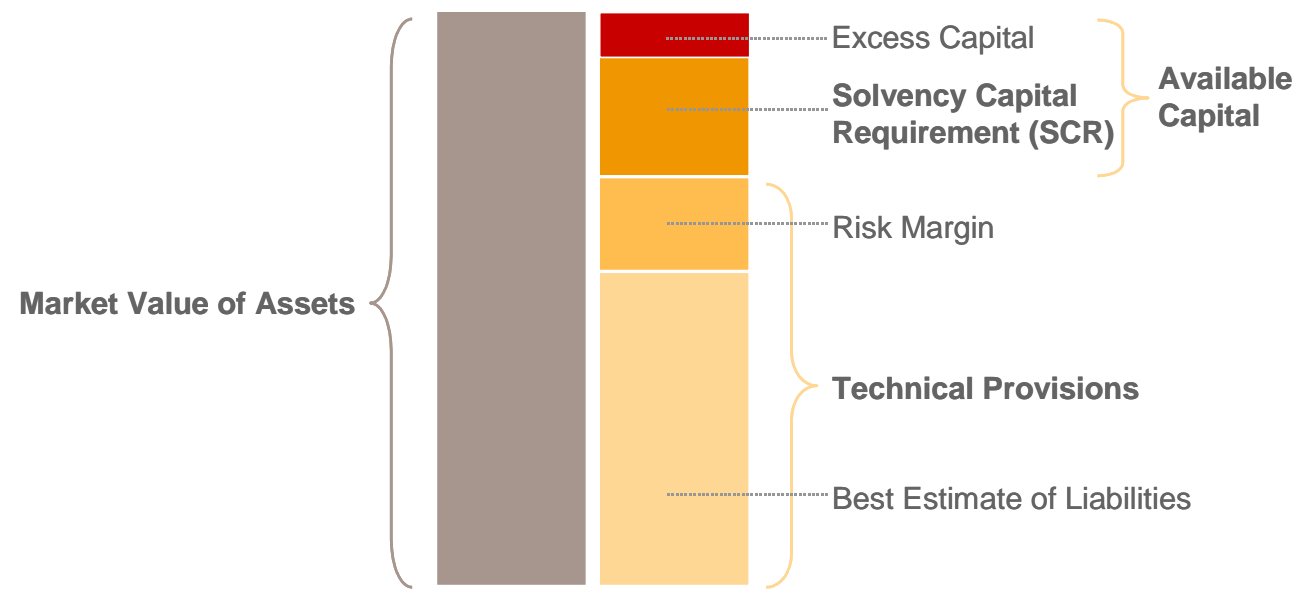

\section{Technical Provisions}

As a basic principle, the QIS 3 model requires a market consistent valuation of assets and liabilities using a total balance sheet approach. This is quite straightforward for the assets, where market values are normally available (mark-to-market) or can be derived (mark-to-model). Since pension liabilities of the pension plans are typically not hedgeable (e.g. due to the embedded longevity risk), a market value for pension liabilities is usually not available. The valuation of pension liabilities is therefore split into two parts, the Best Estimate of Liabilities (BEL) and the Risk Margin.

The BEL is equal to the expected present value of all potential cash flows arising from the pension promises calculated according to the following principles':

- Valuation based on already accrued benefits (no allowance for future accruals);

- Realistic assumptions including future expenses (best estimate);

- $\quad$ Risk free discounting (based on swap curve);

- Allowance for market value of options and guarantees (BEL has to include both guaranteed benefits and extra benefits e.g. due to future conditional indexation).

The Technical Provisions must also include a Risk Margin that meets the objectives either to transfer the portfolio to a third party or to recapitalize the pension fund to ensure a proper run-off by the original undertaking. Underlying assumptions can be summarized as follows ${ }^{10}$ :

- Assume that the pension fund becomes insolvent at the end of the first year due to economic loss and that the portfolio of assets and liabilities is taken over by another pension fund (reference pension fund).

9 See CEIOPS (2007), "QIS 3 Technical Specifications, Part I: Instructions", http://www.ceiops.eu/media/files/consultations/QIS/QIS3/QIS3TechnicalSpecificationsPart1.PDF, p. 7-11.

10 See CEIOPS (2007), "QIS 3 Technical Specifications, Part I: Instructions", http://www.ceiops.eu/media/files/consultations/QIS/QIS3/QIS3TechnicalSpecificationsPart1.PDF, p. 1116. 
- The reference pension fund has to be compensated for additional SCR it has to put up during the whole run-off of the portfolio.

- Assume that the reference pension fund would eliminate investment risk (resulting in zero SCR for market risks from year 2 onwards; only life underwriting and operational risk remain).

The Risk Margin is equal to the present value of the cost of future SCR that the reference pension fund will have to put up during the run-off of the portfolio of assets and liabilities for the in-force book of business at the end of next year $(\mathrm{t}=1)$.

The Technical Provisions (TP) equals the sum of BEL and Risk Margin. The difference between the market value of the assets and the TP gives the Available Capital that can be used to absorb risks.

\section{$S C R$}

The SCR calculation is based on the following principles ${ }^{11}$ :

- The SCR should deliver a level of capital that enables an insurance undertaking to absorb significant unforeseen losses and gives reasonable assurance to policyholders (plan members) that payments will be made as they fall due.

- It should reflect the amount of capital required to meet all obligations over a specified time horizon (1 year) to a defined confidence level $(99.5 \%)$.

- In doing so, the SCR should limit the risk that the level of available capital deteriorates to an unacceptable level at any time during the specified time horizon.

- The SCR should take into account all significant, quantifiable risks (including market risks, life underwriting risks and operational risk).

This means that the SCR corresponds to a 1-year Value-at-Risk with a 99.5\% confidence level - with 99.5\% probability, the Available Capital (defined as market value of assets minus Technical Provisions) will not reduce by more than the SCR over the next year.

In the QIS 3 framework, capital requirements are first calculated separately for each individual type of risk assuming a worst-case change in the underlying risk factor (e.g. a drop of $32 \%$ in the index for global equity investments). The capital requirements for the different risk factors are then aggregated using predefined correlation matrices (so called variance-covariance approach). The risk factors considered in QIS 3 are illustrated in Figure 5, where the risks that are relevant for the generic pension funds are highlighted. The other risks are not relevant for pension funds and are therefore not considered further.

11 See CEIOPS (2007), “QIS 3 Technical Specifications, Part I: Instructions”, http://www.ceiops.eu/media/files/consultations/QIS/QIS3/QIS3TechnicalSpecificationsPart1.PDF, p. 3133. 
Figure 5. Risks for pension funds in the QIS 3 model

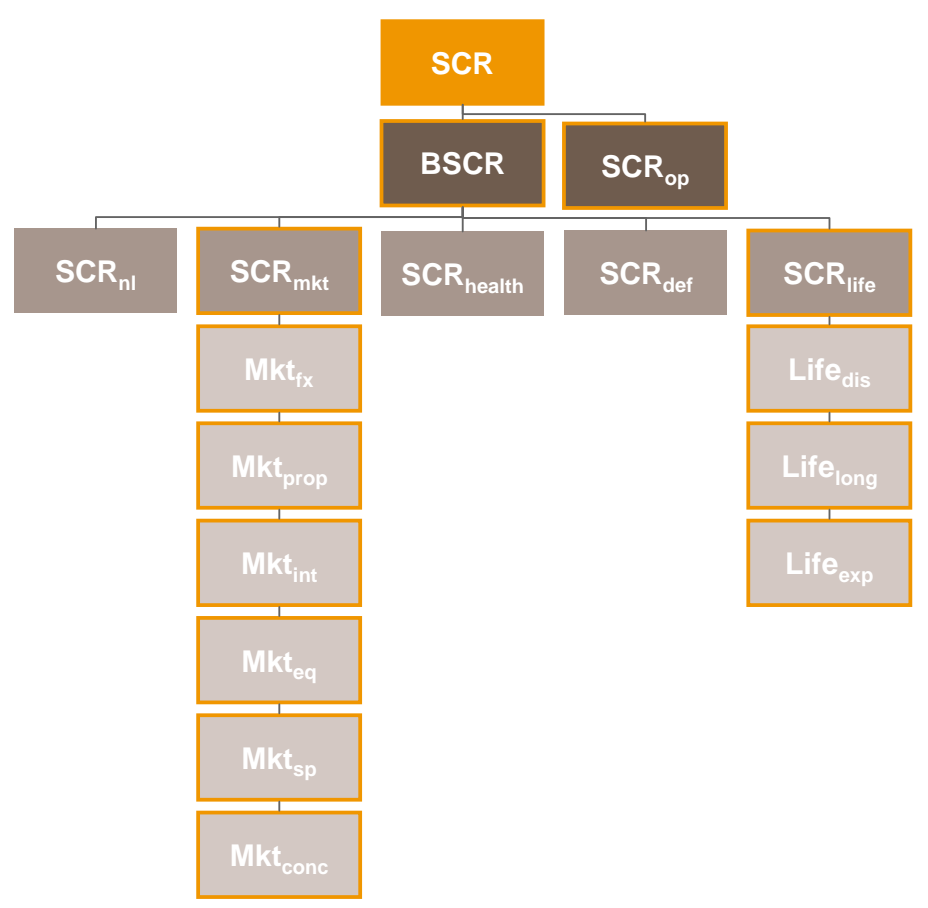

\section{Pension Funds: Adjustments to QIS 3 Framework}

As mentioned above, the QIS 3 framework was initially designed for (life) insurance companies. It clearly needs refinements in order to reflect all risks relevant to pension funds. Two possible modifications are analysed in this study resulting in an adjusted QIS 3 model.

First, the impact of inflation changes on the pension fund's liabilities is assessed in more detail. As explained above, the market consistent valuation of pension liabilities depends on the level of nominal interest rates (for discounting) and on the implied inflation (for future indexations and/or salary increases). Under QIS 3, allowance for the risk related to a change of nominal interest rates is made, but it is not stated to what extent this change is caused by inflation and/or real rate changes.

We propose to split the nominal interest rate risk into two components - inflation risk and real rate risk - and to replace the (nominal) interest rate risk in the QIS 3 model by the aggregated values for inflation and real rate risk. This is illustrated in Figure 6.

Figure 6. Interest risk in the adjusted QIS 3 model

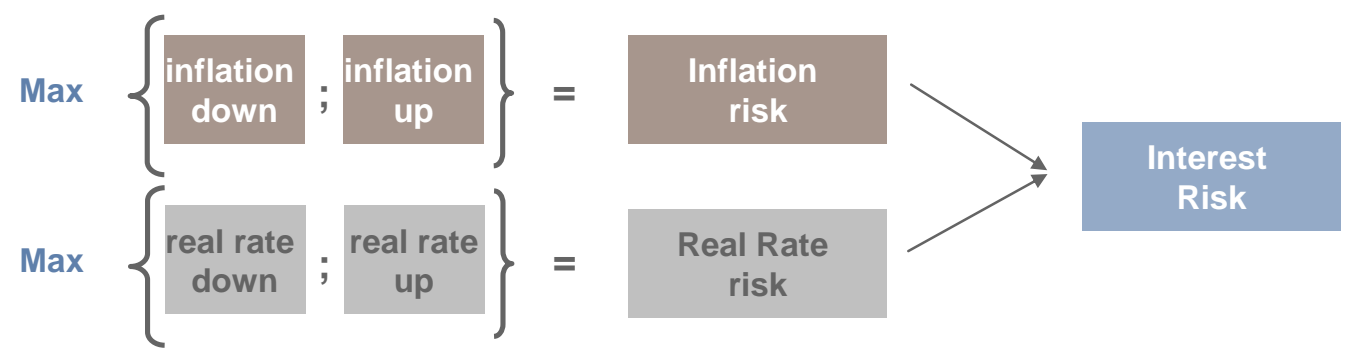

Second, an additional module reflecting salary increase risk seems necessary (in particular for final pay plans). The salary increase risk is defined as the risk that future salary increases differ from best 
estimate assumptions (underlying the BEL calculation), but only to the extent that this is not related to general price inflation $(\mathrm{CPI}){ }^{12}$

We assume that a salary increase of $1.0 \%$ p.a. above best estimate assumptions corresponds to a $99.5 \%$ security level for salary increase risk. Zero correlation is assumed with other underwriting risks (longevity, disability and expense risk).

\section{Results}

In this section the results for the different generic pension plans will be presented. We start with the pension plans without risk sharing features. The main focus will be on the final pay plan. In the second part, the results for the pension plans with risk sharing will be shown.

\section{Final Pay Plan}

The result of the market consistent valuation of assets and liabilities of the final pay plan is shown in Figure 7. Compared to the IAS 19 DBO $(791 \mathrm{~m})$, the Technical Provisions under QIS 3 (985m) are approximately $25 \%$ higher although the same valuation method is applied (project unit credit method based on accrued benefits including allowance for future salary increases ${ }^{13}$ ). This difference can be explained as follows:

- Discount rate: For the BEL, the expected benefit payments are discounted using the risk free term structure $^{14}$ whereas the IAS 19 DBO uses a single discount rate which is the sum of the risk free yield and the AA corporate spread (which is assumed to be equal to 50 basis points). This results in lower discount rates under Solvency II and thus increases the BEL.

- $\quad$ The IAS 19 DBO does not include a Risk Margin.

This leads to a drop in the funding level from $100 \%$ (based on IAS 19) to $80 \%$ (based on QIS 3).

\footnotetext{
${ }^{12}$ Inflation risk is covered separately (see above).

${ }^{13}$ We acknowledge that allowance for future salary increases in the context of solvency assessments needs further considerations.

${ }^{14}$ In QIS 3, the risk free term structure was based on swap rates. CEIOPS is currently considering to use government rates for future QIS (resulting in a further increase of the BEL).
} 
Figure 7. Market consistent valuation for final pay plan

IAS 19

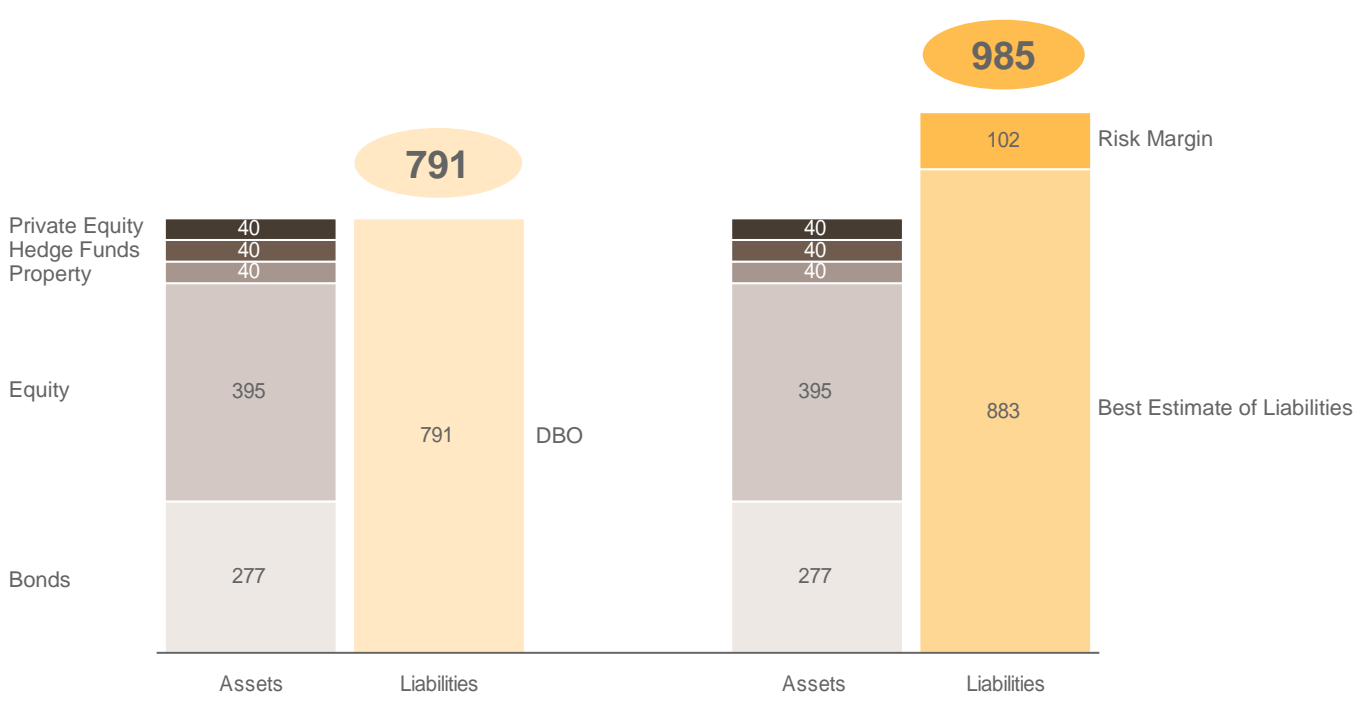

On top of the Technical Provisions, the QIS 3 model requires additional capital to back the SCR. Overall SCR for the final pay plan amounts to $228 \mathrm{~m}$ (26\% of BEL), based on the standard QIS 3 model. Figure 8 shows that the main drivers of the SCR are equity, interest rate and longevity risk.

Figure 8. SCR for the final pay plan

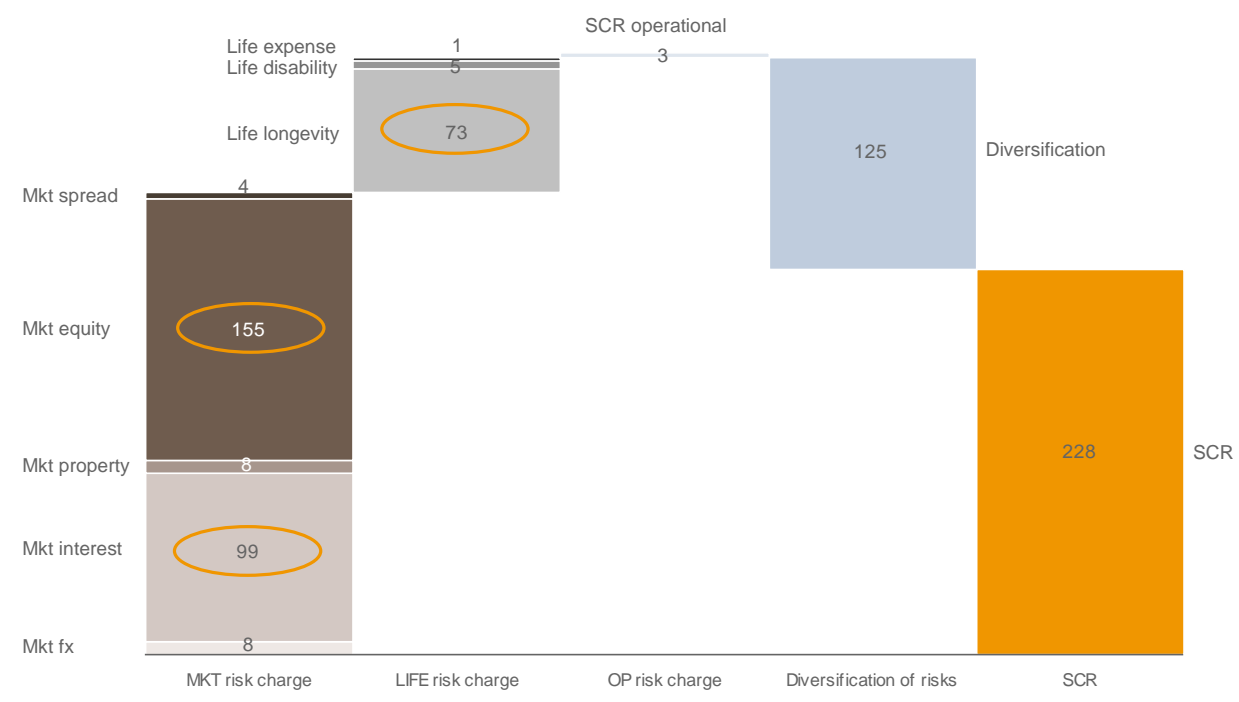

After allowing for the SCR, the funding level based on QIS 3 reduces to $65 \%$. This shows that the solvency requirements would not be fulfilled for the generic final pay plan (minimum of $100 \%$ funding level is required under Solvency II).

Conversely, in order to fulfil the funding requirements, the amount of assets would need to be increased by $65 \%$ (i.e. amount of assets would need to be equal to $165 \%$ of the IAS 19 DBO in order to arrive at a Solvency II funding ratio of $100 \%$ ). 
Figure 9. Results modified QIS 3 model for final pay plan
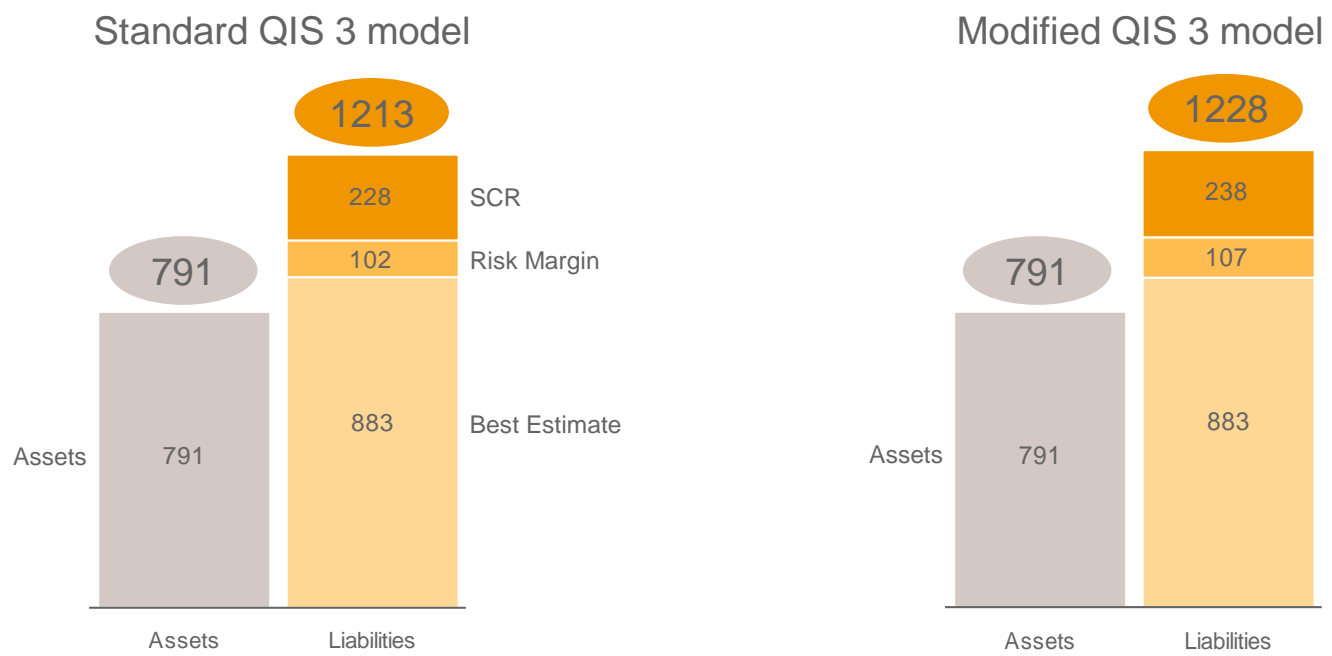

Another possibility would be to decrease the SCR by adjusting the asset allocation. For example, a reduction of equity risk would be achieved by reducing the equity exposure (which is $50 \%$ of total assets for the moderate SAA). The asset allocation is an important driver of the SCR. The results for other SAA can be found in the appendix. Furthermore, a better match of assets and liabilities would reduce the interest riskResults for the modified QIS 3 model (i.e. including allowance for salary increase risk and refined modelling of interest rate risk) are similar. Both SCR and Risk Margin increase slightly (see Figure 9).

\section{Other pension plans without risk sharing}

For the other pension plans without risk sharing, similar calculations were made using the same assumptions. ${ }^{15}$ Results for the adjusted QIS 3 model are shown in Figure 10.

Figure 10. Results for plans without risk sharing (modified QIS 3 model)

\begin{tabular}{|c|c|c|c|c|c|c|}
\hline Pension Plan & Assets* & $\begin{array}{l}\text { Technical } \\
\text { Provisions }\end{array}$ & SCR & Liabilities & $\begin{array}{l}\text { Funding level } \\
\text { Solvency II }\end{array}$ & $\begin{array}{l}\text { Funding level: } \\
\text { minimum IAS }\end{array}$ \\
\hline $\begin{array}{l}\text { Final Pay: } \\
\text { indexation of benefits }\end{array}$ & 791 & 990 & 238 & 1228 & $64 \%$ & $169 \%$ \\
\hline $\begin{array}{l}\text { Career Average: } \\
\text { unconditional indexation }\end{array}$ & 607 & 741 & 172 & 913 & $66 \%$ & $164 \%$ \\
\hline $\begin{array}{l}\text { Career Average: } \\
\text { unconditional indexation: }\end{array}$ & 518 & 624 & 143 & 767 & $68 \%$ & $160 \%$ \\
\hline
\end{tabular}

Assets are equal to $100 \%$ of

corresponding DBOIAS

Absolute numbers differ due to different underlying liabilities. However, there are only minor differences with respect to the funding level based on QIS 3. For all plans, the Solvency II requirements would not be fulfilled if the initial IAS 19 funding level is $100 \%$ and funding would need to increase significantly in order to do so.

\section{Pension plans with risk sharing}

As discussed in section 2.1.2, risk sharing with the sponsoring company and (different generations of) plan members via the contribution policy is an important feature of pension funds that distinguishes them from life insurance companies. A lower security level could be defined in order to reflect this. We

\footnotetext{
${ }^{15}$ See section 2.2
} 
therefore illustrate the results for the career average plan (with unconditional indexation of benefits only) using a $97.5 \%$ security level. For this purpose, publicly available information about the calibration of the QIS 3 stresses ${ }^{16}$ has been used to recalibrate the stresses to this new security level. ${ }^{17}$

Figure 11 shows that the SCR reduces by $29 \%$. A similar decrease can be observed for the Risk Margin since it is closely linked to the SCR. Obviously, the BEL does not change. Although the funding level increases from $68 \%$ to $73 \%$, the Solvency II requirements are still not satisfied.

\section{Figure 11. Results for different security level (modified QIS 3 model)}
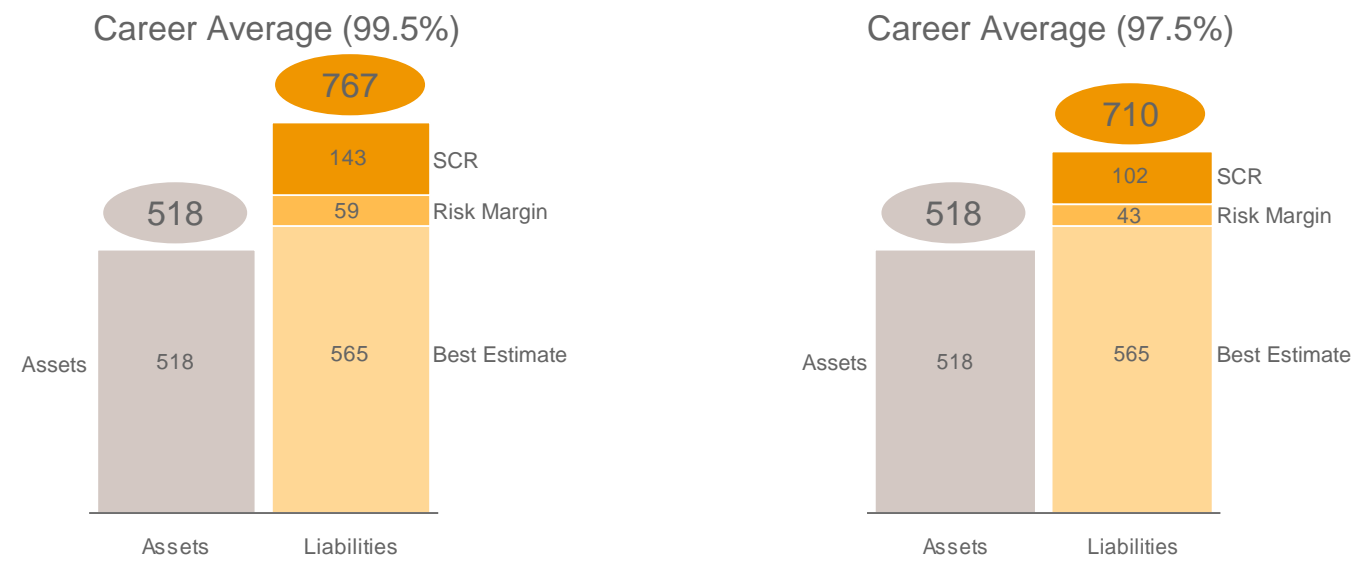

In order to illustrate the impact of risk sharing between the pension fund and the plan members via conditional indexation, we compare the QIS 3 results for the following pension funds:

- Pension fund 1: Career average pension plan with unconditional indexation and initial funding level of $100 \%$ based on IAS 19.

- Pension fund 2: Career average pension plan with conditional indexation and the same amount of assets as pension fund 1. This corresponds to an initial funding level of 143\% based on IAS 19 .

The results of the Solvency II calculations are shown in Figure 12 for both pension funds.

16 See CEIOPS (2007), "QIS 3 Calibration of the underwriting risk, market risk and MCR", (http://www.ceiops.eu/media/files/consultations/QIS/QIS3/QIS3CalibrationPapers.pdf)

${ }^{17}$ This is done for all relevant stresses except for operational risk where a factor-based approach has been used. In most cases, the recalibration is based on the assumption of a normal or lognormal distribution of the underlying risk factors. 
Figure 12. Results conditional indexation (modified QIS 3)
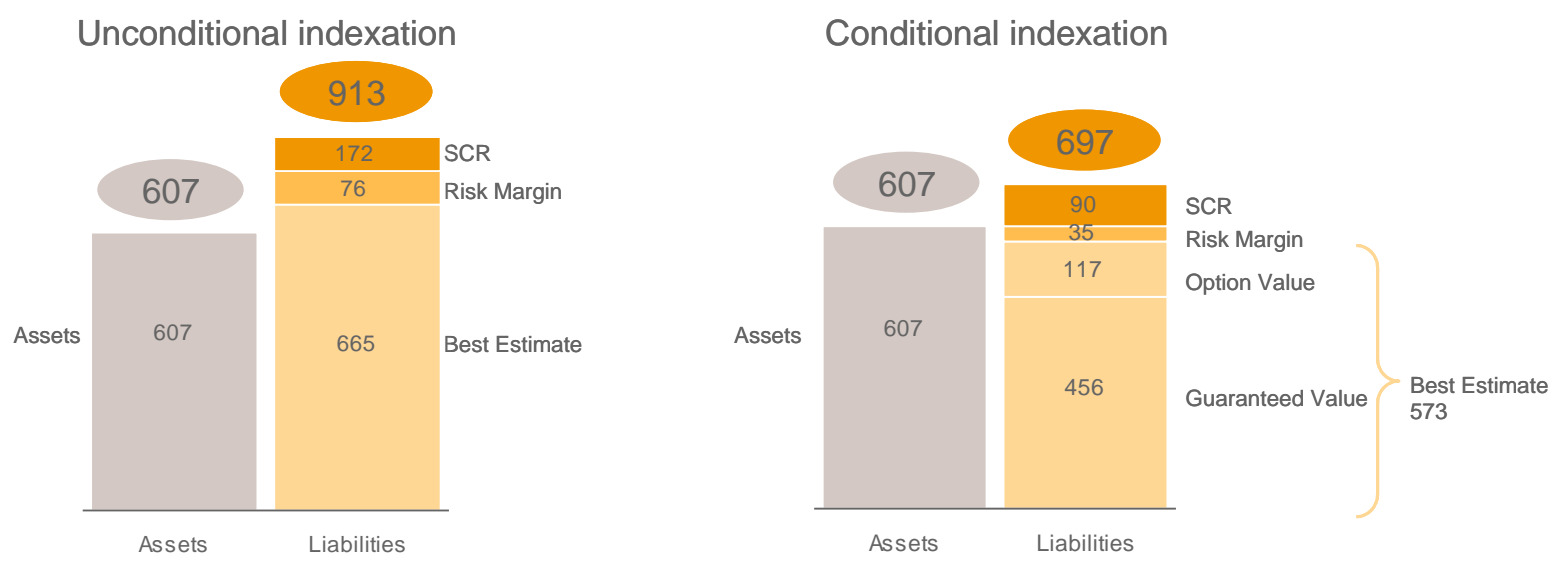

Opposed to the IAS 19 DBO, the BEL under QIS 3 has to include the time value of options and guarantees. The market consistent value of future indexations is therefore part of the BEL under QIS 3 for the pension plan with conditional indexation. This is to some extent comparable to discretionary future profit sharing appearing in traditional participating life insurance contracts.

The value of this option is determined using market consistent valuation techniques based on Monte Carlo simulations. The amount of indexation at each point in time in each scenario depends on the IAS 19 funding level (where the IAS $19 \mathrm{DBO}$ at each point in time reflects past indexations but does not include future indexations). A management rule is defined that describes the amount of indexation as a function of this funding level.

For the generic pension fund with conditional indexation, the BEL amounts to $573 \mathrm{~m}$, which is $14 \%$ lower than the BEL of the pension fund with unconditional indexation. Since the BEL of a pension plan without indexation would be $456 \mathrm{~m}$, the value of future indexations equals $117 \mathrm{~m}$ ( $26 \%$ of the BEL for guaranteed benefits).

Compared to the pension fund with unconditional indexation, the SCR reduces by $48 \%$ (from $172 \mathrm{~m}$ to $90 \mathrm{~m})$. This is due to the fact that allowance is made for risk sharing with the plan members. In bad scenarios (where the funding level decreases), the amount of future indexations also decreases (i.e. the option value decreases). Therefore the change in the market value of assets (e.g. in an equity stress) can be partially mitigated by a corresponding change in BEL.

Overall, the funding level based on QIS 3 is still below 100\% for the pension fund with conditional indexation. However, it should be noted that the results are somewhat distorted by the fact that the amount of indexation is derived from the IAS 19 funding level (as currently practised), but the valuation of liabilities is made on a market consistent basis. If a market consistent valuation framework would be introduced, it would seem natural to also adjust the indexation rules in order to have a consistent overall setting.

Another observation is that this option value and as a result the BEL would increase further if the amount of assets would be increased (since plan members would receive higher indexations). If the amount of assets reaches a certain level, the BEL would be equal to the BEL for the pension fund with unconditional indexation. An increase in the amount of assets would also have an impact on the solvency capital requirements for market risks (due to the larger amount of assets subject to the stresses) and on the amount of risk mitigation recognized under QIS 3 (due to higher option values before stress). As a 
consequence, the SCR would change as well. ${ }^{18}$ It is conceivable that in some situations an increase of the amount of assets would be offset to a large extent by increases of the BEL and SCR. ${ }^{19}$

Benefit cuts are another way for pension funds to share risks with plan members. When the funding level of the pension fund is below a certain level (in our case 100\%), the benefit payments are cut. This means that the plan members cover some part of the losses of the pension fund if the funding level of the pension fund deteriorates.

The results of the career average plan with the option to cut benefits have been compared to the results of the standard career average plan in Figure 13.

Figure 13. Results benefit cuts (modified QIS 3)

\begin{tabular}{|c|c|c|c|c|c|}
\hline Pension Plan & Assets* & $\begin{array}{l}\text { Technical } \\
\text { Provisions }\end{array}$ & SCR & Liabilities & $\begin{array}{l}\text { Funding level: } \\
\text { Solvency II }\end{array}$ \\
\hline $\begin{array}{l}\text { Career Average: } \\
\text { benefit cuts }\end{array}$ & 518 & 460 & 45 & 505 & $103 \%$ \\
\hline $\begin{array}{l}\text { Career Average: } \\
\text { unconditional indexation: benefits only }\end{array}$ & 518 & 624 & 143 & 767 & $68 \%$ \\
\hline
\end{tabular}

The technical provisions and the SCR decrease significantly due to the option to cut benefits resulting in a funding level of $103 \%$ under Solvency II. The funding level of the standard career average plan without the option to cut benefits amounts to only $68 \%$.

Benefit cuts can be seen as a put option that the plan members have sold to the pension fund. It is important to recognize that the value of this option depends on the management rules for benefit cuts. When the funding level at which benefits are cut is set at a lower level (e.g. 90\%), the value of this risk sharing feature is smaller. In this case, only modest reductions in Technical Provisions and SCR would be observed compared to the career average plan without the option to cut benefits.

Overall, the Solvency II funding level of the pension plans with risk sharing features is higher compared to the plans without risk sharing. The amount of improvement varies depending on the type of risk sharing and the associated management rules.

\section{Conclusions}

The target of this study was to analyse what the quantitative funding requirements would be, if Solvency II (based on the QIS 3 methodology) would be applied to pension funds with defined benefit plans. In addition, possible extensions of the Solvency II methodology were discussed in order to reflect the specifics of pension funds.

The results can be summarized as follows:

\footnotetext{
${ }^{18}$ At this point, it is important to recall that the SCR is based on the change of all assets held by the pension fund and not only on the assets needed to cover the liabilities. Thus, giving more assets to a pension fund that is already overfunded would increase the SCR under the QIS 3 model (which seems counterintuitive).

${ }^{19}$ Conversely, a reduction of the amount of assets would lower the BEL (since the value of future indexations would decrease). Hence the decrease in funding level would be less severe than for a pension plan with unconditional indexation.
} 
- Compared to an initial funding level of $100 \%$ based on IAS 19, Solvency II would require a dramatic increase in funding level for pension funds.

- Significant changes in asset allocation are necessary in order to reduce SCR (e.g. lower equity exposure).

- The Solvency II methodology makes allowance for risk sharing with plan members. This leads to a reduction of SCR.

- The QIS 3 model has to be modified in order to account for the specific risks of pension funds, in particular regarding inflation risk and salary increase risk.

- Further conceptual work seems necessary in order to properly reflect risk sharing with sponsoring company or plan members (e.g. via reduced security level or based on credit rating of sponsoring company).

It is important to understand that the results may vary significantly between countries and between different types of pension funds. We therefore recommend additional analyses that reflect the situation in specific countries (e.g. initial funding level, asset allocation, type of pension plan). Similarly, possible consequences of the introduction of Solvency II for pension funds (e.g. impact on contribution rates, plan design and asset allocation) need further investigations. 


\section{APPENDIX}

In this appendix, we present the results for the final pay plan for different plan member portfolios and for different asset allocations.

\section{A1: Sensitivity Analysis: Mix of plan members}

Two different mixes of plan members have been assumed: "Less Actives" and "Retirees" (see Figure 14). In the "Less Actives" portfolio the amount of active members and early leavers has been reduced. The "Retirees" portfolio consists of $100 \%$ retirees.

Figure 14. Mixes of plan members
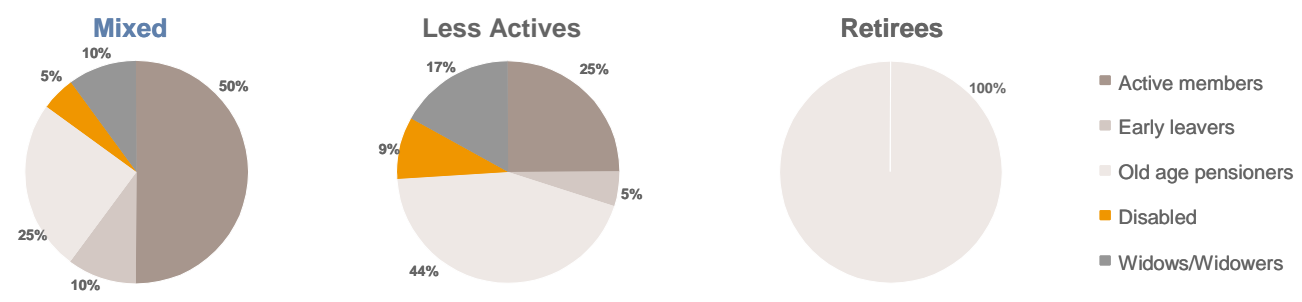

The results for the final pay plan show that an IAS 19 funding level of $100 \%$ is not sufficient to fulfil the Solvency II requirements for all considered mixes of plan members (see Figure 15). The Solvency II funding level improves however for the "Less Actives" (71\%) and the "Retirees" portfolio (74\%) compared to the "Mixed" portfolio (64\%). The main reason is that the difference between the IAS 19 DBO and the BEL is smaller for the other two mixes due to a lower IAS 19 DBO discount rate (which in turn depends on the duration of the benefit payments).

Figure 15. Final pay plan results for different mixes of plan members

\begin{tabular}{|l|c|c|c|c|c|}
\hline Final Pay Plan with & Assets & $\begin{array}{c}\text { Technical } \\
\text { Provisions }\end{array}$ & SCR & Liabilities & $\begin{array}{c}\text { Funding level: } \\
\text { Solvency II }\end{array}$ \\
\hline Mixed portfolio & 791 & 990 & 238 & 1228 & $64 \%$ \\
\hline Less Actives portfolio & 766 & 874 & 207 & 1081 & $71 \%$ \\
\hline Retirees portfolio & 1040 & 1133 & 281 & 1414 & $74 \%$ \\
\hline
\end{tabular}

\section{A2: Sensitivity Analysis: Asset Allocation}

The asset allocation has a significant impact on the solvency requirements for the pension fund under Solvency II. Two different asset allocations have been assumed: "Defensive" and "Aggressive". Figure 3 shows the weights of the different asset classes in these two asset portfolios. The "Defensive" asset allocation has a larger share of bond investments ( $80 \%$ instead of 35\%), whereas the "Aggressive" portfolio is mainly invested in equities (65\%) and alternatives (15\%). 
The SCR for the final pay plan with the "aggressive" asset allocation increases due to the higher equity risk charge. Although the SCR for the final pay plan with the defensive asset allocation is reduced, the funding level under Solvency II is still below 100\% (see Figure 16).

Figure 16. Final pay plan results for different asset allocations

\begin{tabular}{|c|c|c|c|c|c|}
\hline Final Pay Plan with & Assets & $\begin{array}{l}\text { Technical } \\
\text { Provisions }\end{array}$ & SCR & Liabilities & $\begin{array}{l}\text { Funding level: } \\
\text { Solvency II }\end{array}$ \\
\hline Defensive SAA & 791 & 986 & 170 & 1156 & $68 \%$ \\
\hline Moderate SAA & 791 & 990 & 238 & 1228 & $64 \%$ \\
\hline Aggressive SAA & 791 & 992 & 272 & 1264 & $63 \%$ \\
\hline
\end{tabular}




\section{REFERENCES}

Blome, S., Fachinger, K., Franzen, D., Scheuenstuhl, G., and Yermo, J. (2007), "Pension Fund Regulation and Risk Management: Results from an ALM Optimisation Exercise", in OECD Private Pension Series No. 8, Protecting Pensions: Policy Analysis and Examples from OECD Countries, Paris, OECD.

CEIOPS (2007), "QIS 3 Technical Specifications, Part I: Instructions", http://www.ceiops.eu/media/files/consultations/QIS/QIS3/QIS3TechnicalSpecificationsPart1.PDF.

CEIOPS (2007), "QIS 3 Calibration of the underwriting risk, market risk and MCR”,http://www.ceiops.eu/media/files/consultations/QIS/QIS3/QIS3CalibrationPapers.pdf.

Heubeck, K., Herrmann, R. and D’Souza, G. (2006), ’Die Richttafeln 2005 G - Modell, Herleitung, Formeln“, in Blätter der DGVFM.

McCreevy, C. "Closing address to the CEIOPS Conference 2007 - "View from the Top", Proceedings of CEIOPS Conference 2007, Frankfurt

(http://www.ceiops.eu/media/docman/public_files/Conference2006/CEIOPS\%20ConferenceMcCREEVY-EC.pdf).

Mercer Investment Consulting (2007), "Asset allocation survey: European institutional market place overview".

Terták, E. (2007), “The Supervisory Framework for Occupational Pensions - Where Now and What Next?", Proceedings of CEIOPS Conference 2007, Frankfurt (http://www.ceiops.eu/media/docman/public_files/Conference2006/CEIOPSConferenceElemerTertak-EC.pdf). 